\title{
Vaccinium myrtillus leaves and Frangula alnus bark derived extracts as potential antistaphylococcal agents*
}

\author{
Beata Sadowska1凶, Małgorzata Paszkiewicz¹, Anna Podsędek², Małgorzata Redzynia² and \\ Barbara Różalska1
}

'Department of Infectious Biology, Faculty of Biology and Environmental Protection, University of Lodz, Łódź, Poland; ${ }^{2}$ Department of Biotechnology and Food Sciences, Institute of Technical Biochemistry, Lodz University of Technology, Łódź, Poland

\begin{abstract}
Due to constantly increasing antibiotic resistance of pathogens and participation of the biofilms they make in various types of infections, a development of alternative therapeutic strategies becomes an urgent need. Taking advantage of the biological activity of plant-derived compounds can solve this problem. In this study antimicrobial, including those synergistic with classic antibiotics, and cytotoxic properties of newly-obtained extracts from Vaccinium myrtillus leaves (VLE) and Frangula alnus bark (FBE) were evaluated. Both tested extracts exhibited relevant antistaphylococcal activity (MIC range $0.75-$ $1.5 \mathrm{mg} / \mathrm{mL}$ ) accompanied by a relativly low cytotoxic effect on mammalian cells $(\mathrm{BI}>1)$. Phytochemical analysis of the extracts tested showed a high total content of phenolic compounds with the predominance of hydroxycinnamic acids in VLE and hydroxybenzoic acids and flavanols in FBE. Widely described in the literature antimicrobial properties of phenolics were probably connected with the biological activity of the extracts tested. We also report that the presence of VLE or FBE at sub-MIC concentrations enhances biocidal potential of vancomycin and linezolid. Therefore, we are considering a possibility of an alternative therapy for local infections caused by $S$. aureus by combining classic antibiotics with plantderived extracts.
\end{abstract}

Key words: phytocompounds, antimicrobial activity, synergism with antibiotics, biocompatibility index

Received: 31 October, 2013; revised: 11 March, 2014; accepted: 17 March, 2014; available on-line: 20 March, 2014

\section{INTRODUCTION}

Traditional therapy against bacterial infections has become ineffective since the number of strains resistant to antibiotics and participation of microbial biofilm in the development of infectious lesions is constantly increasing. Research into new treatment options effective against both, planktonic and biofilm forms of microbial life, involves looking for the substances with various types of activity. These could be compounds which not only have direct antimicrobial properties but also exhibit synergistic effect with classic pharmacological agents (enhance or restore their activity), restrict the expression of microbial virulence factors, prevent microbial adhesion and aggregation or activate host immune defense mechanisms designed to combat infections (Budzyńska et al., 2011; Cushnie \& Lamb, 2011; Gauwerky et al., 2009; Kurlenda \& Grinholc, 2012; Kuźma et al., 2012). Nature may be a good source of such substances. Health-promoting and antimicrobial properties of natural substances have been used in folk medicine for thousands of years, even despite the lack of knowledge of their mechanisms of action. Many plant extracts or other formulations prepared as infusions, decoctions, or poultices are used even until today in modern phytomedicine. They often possess multidirectional biological properties such as antioxidant, anti-inflammatory, anti-allergic, anti-tumor and antimicrobial activities (Alviano \& Alviano, 2009; Budzyńska et al., 2011; Fraga et al., 2010; Różalski et al., 2013; Rösch et al., 2003; Tegos et al., 2002). Plant-derived products exhibiting antimicrobial activity usually fall into a class of phytoalexins - secondary metabolites synthesized to prevent insect, fungal and microbial infections and to repair tissue damage. Among them, polyphenols (with the largest and the best known group of flavonoids) and essential oils are the most promising. Important advantages of most of the natural products include their wide-spectrum of activity and effectiveness irrespective of the drug susceptibility of target microorganisms, demonstrating at the same time an extremely low risk of giving rise to resistance mechanisms (Bakkali et al., 2008; Budzyńska et al., 2011; Chaieb et al., 2011; Cushnie \& Lamb, 2005; 2011; Fankam et al., 2011; Martos et al., 2013).

The aim of our study was to test antimicrobial activity, including that synergistic with classic antibiotics, of newly-prepared plant extracts from Vaccinium myrtillus leaves (VLE) and Frangula alnus bark (FBE). In addition, commercially available polyphenol-type phytocompounds such as gallic acid, carvacrol, and oleanolic acid were examined. According to phytochemical analysis, these compounds are (among others) ingredients of the tested extracts. We considered a possibility of using phytocompounds in supporting treatment of local skin infections caused by staphylococci. To our knowledge, both plantderived extracts have not yet found practical and clinically approved application in this area. Due to the literature data on the negative effects of some components of

e-mail: bsad@biol.uni.lodz.pl

*A preliminary report from the individual stages of this research was presented at the $3^{\text {rd }}$ Workshop on Microbiology in Health and Environmental Protection - MIKROBIOT 2013 in Łódź, Poland.

Abbreviations: $\mathrm{BI}$, biocompatiblity index; CFU, colony forming units; DMSO, dimethyl sulfoxide; $\mathrm{Et}-\mathrm{OH}$, ethanol; FBE, Frangula alnus bark extract; FCS, fetal calf serum; HPLC, high-performance liquid chromatography; $\mathrm{MBC}$, minimum bactericidal concentration; MHA, Müeller-Hinton Agar; MHB, Müeller-Hinton Broth; MIC, minimum inhibitory concentration; VLE, Vaccinium myrtillus leaves extract 
plant extracts on eukaryotic cell viability and functions, cytotoxicity tests on mouse fibroblasts line L929 were also performed for each phytocompound.

\section{MATERIALS AND METHODS}

Plant materials, extraction and isolation of phytocompounds. Bark of Alder Buckthorn (Frangula alnus) was in a form of commercial samples supplied by KAWON-HURT Nowak Sp.j. (Gostyń, Poland). Leaves of European blueberry (V accinium myrtillus) were collected in August 2010 in the forest near Łódź (central Poland). The plant material was air-dried at $60^{\circ} \mathrm{C}$ for $4 \mathrm{~h}$, ground to fine powder and stored in a refrigerator. The dry leaves $(10 \mathrm{~g})$ or bark (20 g) were extracted with acetone-water $(70: 30, \mathrm{v} / \mathrm{v})$ at a solid to liquid ratio $1: 10$ $(\mathrm{w} / \mathrm{v})$, at room temperature for $30 \mathrm{~min}$ and then centrifuged at $2500 \times g$ for $15 \mathrm{~min}$. The pellets were re-extracted twice with $70 \%$ aqueous acetone for $15 \mathrm{~min}$ and the supernatants were combined. After removal of acetone with a vacuum rotary evaporator (Rotavapor RII, Büchi, Switzerland) at $<40^{\circ} \mathrm{C}$, the extracts were subjected to liquid-liquid partition with chloroform $(1: 1, \mathrm{v} / \mathrm{v})$ three- and eight-times, for blueberry leaves and Alder Buckthorn bark respectively. The water fractions were concentrated under vacuum at $<40^{\circ} \mathrm{C}$ and the remaining extracts were lyophilized (Alpha 1-2 LD plus, Christ) to yield $1.597 \mathrm{~g}$ of blueberry leaves extract (VLE) and 2.920 $\mathrm{g}$ of Alder Buckthorn bark extract (FBE). The VLE and FBE extracts were assessed for their biological activities and chemical profile. Dried extracts were reconstituted at $5 \mathrm{mg} / \mathrm{mL}$ in water before chemical analysis.

Phytochemical analysis. Quantification of the phenolic profile by HPLC method. HPLC-PDA analysis of different groups of phenolic compounds was performed by using analytical reversed-phase HPLC system (Waters) with an autosampler 2707 and binary HPLC pump 1525 coupled to a 996 photodiode array detector (2998), controlled by the Waters Breeze 2 software (Waters, Milford, MA). Separation was performed on a SYMMETRY C18 column $(250 \mathrm{~mm} \times 4.6 \mathrm{~mm}, 5 \mu \mathrm{m}$, Waters $)$. The binary mobile phase according to Dyrby et al. (2001) consisted of water and formic acid in the ratio of 90:10 (v/v), respectively (solvent A), water, acetonitrile and formic acid in the ratio of 49:50:10 (v/v/v), respectively (solvent B). Separation of phenolics was performed using the following gradient program with a flow rate of $1 \mathrm{~mL} / \mathrm{min}: 0$ $\min , 88 \% \mathrm{~A}+12 \% \mathrm{~B} ; 26 \min , 70 \% \mathrm{~A}+30 \% \mathrm{~B} ; 40-$ $43 \mathrm{~min}, 0 \% \mathrm{~A}+100 \% \mathrm{~B}$; $43-50 \mathrm{~min}, 88 \% \mathrm{~A}+12 \% \mathrm{~B}$. On the basis of spectral identification and maximum of UV-Vis absorption, the phenolics obtained were qualified into four subclasses: flavanols and hydroxybenzoic acids (detection at $280 \mathrm{~nm}$; expressed as $\mathrm{mg}$ of gallic acid equivalents/g of extract), hydroxycinnamic acids (detection at $320 \mathrm{~nm}$; expressed as $\mathrm{mg}$ of chlorogenic acid equivalents/g of extract), flavonols (detection at 360 $\mathrm{nm}$; expressed as $\mathrm{mg}$ of rutin equivalents/g of extract), and anthocyanins (detection at $520 \mathrm{~nm}$; expressed as $\mathrm{mg}$ of cyanidin 3-glucoside equivalents/g of extract).

Determination of total flavanols. Total flavanol content in extracts was determined by the vanillin assay method described by Swain and Hillis (1959). The following reaction mixtures a: $0.1-2 \mathrm{~mL}$ sample $+4 \mathrm{~mL}$ $1 \%$ vanillin in $70 \% \mathrm{H}_{2} \mathrm{SO}_{4}, \mathrm{~b}: 0.1-2 \mathrm{~mL}$ sample +4 $\mathrm{mL} 70 \% \mathrm{H}_{2} \mathrm{SO}_{4}$, c: $2 \mathrm{~mL}$ water $+4 \mathrm{~mL} 1 \%$ vanillin in $70 \% \mathrm{H}_{2} \mathrm{SO}_{4}$ and $\mathrm{d}: 2 \mathrm{~mL}$ water $+4 \mathrm{~mL} 70 \% \mathrm{H}_{2} \mathrm{SO}_{4}$ were prepared and incubated for $10 \mathrm{~min}$ in a cold water bath. The mixtures were measured at $500 \mathrm{~nm}$ using
UV-Vis spectrophotometer (Unicam, England). Absorbance was calculated as: $\mathrm{A}=\left(\mathrm{A}_{\mathrm{a}}-\mathrm{A}_{\mathrm{b}}-\mathrm{A}_{\mathrm{c}}\right) .(+)$-Catechin was employed as a calibration standard and results were expressed as $\mathrm{mg}$ of $(+)$-catechin equivalents/g of extract.

Determination of total proanthocyanidins. The proanthocyanidins were determined after acid depolymerization to the corresponding anthocyanidins as described by Rösch et al. (2003). The extracts were dissolved in a mixture containing concentrated hydrochloric acid and $n$-butanol $(1: 9, \mathrm{v} / \mathrm{v})$. Then the samples were heated for $90 \mathrm{~min}$ in a boiling water bath. After the solution was cooled to room temperature, the absorbance was read at $550 \mathrm{~nm}$. The content of proanthocyanidins (mg of cyanidin equivalents/g of extract) was calculated by the molar extinction coefficient of cyanidin $\left(\varepsilon=17360 \mathrm{~L} \mathrm{~mol}^{-1} \mathrm{~cm}^{-1}\right.$ and molar mass $287 \mathrm{~g} \mathrm{~mol}^{-1}$ ).

Determination of total hydrolyzable tannins. The content of hydrolyzable tannins was estimated with a high-performance liquid chromatography (HPLC) method after acidic hydrolysis of gallotannins into methyl gallate and acidic hydrolysis of ellagitannins into ellagic acid (Hartzfeld et al., 2002). The methyl gallate and ellagic acid were analyzed directly by HPLC as described above, and quantified as $\mathrm{mg}$ of methyl gallate or ellagic acid equivalents per $1 \mathrm{~g}$ of the extract, respectively.

Commercial phytocompounds. Gallic acid, carvacrol, and oleanolic acid were purchased from Sigma-Aldrich (Germany). Gallic acid and carvacrol were initially dissolved in 96\% ethanol (Et-OH; Sigma-Aldrich, Germany), oleanolic acid in 100\% dimethyl sulfoxide (DMSO; Sigma-Aldrich, Germany), then diluted to tested concentrations in such a way that the final concentration of Et-OH or DMSO did not to exceed $5 \%$ or $2 \%$ for bacteria, respectively, and $0.5 \%$ for eukaryotic cells, which was considered to be safe (not affecting the viability of microbial or eukaryotic cells).

Evaluation of the minimum inhibitory concentration (MIC) and the minimum bactericidal concentration (MBC) of phytocompounds. Reference strain of Stapbylococcus aureus ATCC 29213 and clinical S. aureus H9 strain were used. Bacteria were grown for $24 \mathrm{~h}$ at $37^{\circ} \mathrm{C}$ on Müeller-Hinton Agar — MHA (BTL, Poland) and microbial suspensions $\left(5 \times 10^{5} \mathrm{CFU} / \mathrm{mL}\right)$ were prepared in Müeller-Hinton Broth - MHB (BTL, Poland) based on nephelometric measurements of the suspension at $\mathrm{OD}_{535}$, corresponding to a specified density of staphylococcal suspension. MIC values were determined by a microdilution broth assay according to the Clinical and Laboratory Standards Institute (CLSI) recommendations (2009). Stock solutions of plant-derived extracts and commercial phytocompounds were prepared in 100\% DMSO or $96 \%$ Et-OH. The final highest DMSO or Et$\mathrm{OH}$ concentrations were $1.25 \%$ and $4.8 \%$, respectively, which did not affect bacterial growth. The concentration ranges of tested phytocompounds (in a two-fold dilution system) were $0.375-6.0 \mathrm{mg} / \mathrm{mL}$ for plant-derived extracts and $0.0078-0.5 \mathrm{mg} / \mathrm{mL}$ for commercial phytocompounds, with an extension to the concentration of $0.75 \mathrm{mg} / \mathrm{mL}$ for oleanolic acid. Bacterial suspensions $(100 \mu \mathrm{L})$ were mixed 1:1 with serial dilutions of the phytocompounds and incubated at $37^{\circ} \mathrm{C}$ for $18 \mathrm{~h}$. The highest dilution showing no turbidity was recorded as MIC. Since the color of the extracts at higher concentrations made the reading of turbidity difficult, bacterial growth on MHA $(10 \mu \mathrm{L}$ from each well after vigorous stirring; linear culture incubated for the subsequent $18 \mathrm{~h}$ at $37^{\circ} \mathrm{C}$ ) was tested concurrently. The concentrations of the compounds bactericidal to $\geq 99.9 \%$ of the inoculum (MBC) were determined using the same method. In each case, 
the experiments were carried out in duplicate on two different preparations.

Determination of plant-derived products synergy with the antibiotics by microdilution method. Serial two-fold dilutions of antibiotics, starting from $2 \times$ MIC (final concentration) for each $S$. aureus strain, were prepared in 96-well culture plates (NUNC, Denmark), $50 \mu \mathrm{L} /$ well in MHB. Then, $50 \mu \mathrm{L}$ of tested phytocompounds at final concentrations $1 / 2$ or $1 / 4 \mathrm{MIC}$, and $100 \mu \mathrm{L}$ of bacterial suspensions in $\mathrm{MHB}\left(5 \times 10^{5} \mathrm{CFU} / \mathrm{mL}\right)$ were added to the wells. For the controls of antibiotic activity, $50 \mu \mathrm{L}$ of $\mathrm{MHB}$ was added to the wells instead of plant-derived products. Plates were incubated for $18 \mathrm{~h}$ at $37^{\circ} \mathrm{C}$. The optical density was measured at $600 \mathrm{~nm}$ using a multi-reader Victor2 (Wallac, Finland). Since the color of some plant-derived solutions interfered with optical measurements, $50 \mu \mathrm{L}$ aliquots of each sample were spotted onto MHA plates. After $18 \mathrm{~h}$ incubation at $37^{\circ} \mathrm{C}$, staphylococcal growth intensity was evaluated to confirm MIC values. All experiments were prepared in duplicate. The MIC values of antibiotics alone were compared to those obtained in the presence of phytocompounds to assess the occurrence of a synergistic effect.

Evaluation of phytocompound cytotoxicity towards eukaryotic cells. An immortalized cell line: mouse fibroblasts L929 (recommended for a cytotoxicity test in accordance with EN ISO 10993-5) cultured in RPMI-1640 medium (Sigma, Germany) containing 10\% fetal calf serum (FCS; Cytogen, Poland) and $2 \mathrm{mM} / \mathrm{mL}$ L-glutamine (Sigma, Germany) were used. The monolayer of a 24-h old culture of L929 in 96-wells microplates (cell inoculum: $100 \mu \mathrm{L} /$ well from $1 \times 10^{6} \mathrm{cell} / \mathrm{mL}$ ) was exposed to various concentrations of plant products for $30 \mathrm{~min}$. (minimal exhibition in accordance with the guidelines for cytotoxicity testing) and $24 \mathrm{~h}$ at $37^{\circ} \mathrm{C}$, with $5 \% \mathrm{CO}_{2}$. The concentration ranges of the phytocompounds used in the test (prepared as a two-fold dilution system) were $7.8-2000 \mu \mathrm{g} / \mathrm{mL}$ for the extracts and $3.9-500 \mu \mathrm{g} / \mathrm{mL}$ for commercial phytochemicals. In parallel, the controls of the lowest cytotoxicity (cells treated with the culture medium) and the highest cytotoxicity (cells treated with 2\% Triton X-100; Merck, Germany) were prepared. Then, analysis of phytocompounds cytotoxicity was performed on the basis of activity of lactate dehydrogenase $(\mathrm{LDH})$ released from the damaged/dead cells (LDH Cytotoxicity Kit, Clontech, USA; as recommended by the manufacturer). This study was designed to determine the cytotoxicity index $-\mathrm{IC}_{50}$, understood as the concentration of a phytocompound causing a cy-

Table 1. Phenolic composition ( $\mathrm{mg} / \mathrm{g}$ ) of plant-derived extracts.

\begin{tabular}{|c|c|c|}
\hline & V. myrtillus leaves (VLE) & F. alnus bark (FBE) \\
\hline Total phenolics ${ }^{1}$ & $399.94 \pm 15.31$ & $254.75 \pm 34.90$ \\
\hline Hydroxybenzoic acids + flavanols 2 & $75.56 \pm 2.16$ & $242.73 \pm 33.18$ \\
\hline Hydroxycinnamic acids ${ }^{3}$ & $295.49 \pm 12.10$ & $7.45 \pm 1.53$ \\
\hline Flavonol derivatives ${ }^{4}$ & $28.89 \pm 1.04$ & $4.57 \pm 0.19$ \\
\hline Total flavanols 5 & $25.92 \pm 1.84$ & $56.93 \pm 5.32$ \\
\hline Total proanthocyanidins ${ }^{6}$ & $25.45 \pm 1.18$ & 0 \\
\hline Hydrolyzable tannins ${ }^{7}$ & $1.54 \pm 0.08$ & 0 \\
\hline
\end{tabular}

Values are means \pm S.D., $n \geq 3$. 'sum of different phenolic groups determined by HPLC method; ${ }^{2}$ determined by HPLC method at $280 \mathrm{~nm}$ as gallic acid equivalents; ${ }^{3}$ determined by HPLC method at $320 \mathrm{~nm}$ as chlorogenic acid equivalents; ${ }^{4}$ determined by HPLC at $360 \mathrm{~nm}$ as quercetin equivalents; ${ }^{5}$ determined by vanillin reagent as (+)catechin equivalents; ${ }^{6}$ determined after acid depolymerization as cyanidin equivalents; ${ }^{7}$ determined by HPLC at $280 \mathrm{~nm}$ after acid hydrolysis as ellagic acid equivalents totoxic effect in $50 \%$ of the population of tested cells. Microbiological screening (MBC evaluation), and $\mathrm{IC}_{50}$ were used to calculate the value of BI (biocompatiblity index) based on the formula: $\mathrm{BI}=\mathrm{IC}_{50} / \mathrm{MBC}$. If $\mathrm{BI} \geq$ 1.0 an extract/commercial phytocompound express the best basic biological activity parameters, understood as high antimicrobial activity accompanied by low cytotoxicity towards eukaryotic cells.

\section{RESULTS AND DISCUSSION}

Vaccinium myrtillus (Bilberry) has a long history of medicinal use and its berries have been extensively studied in the recent years. They are known for exceptionally high contents of anthocyanins with powerful antioxidant capacity and many flavonoids. Bilberries possess beneficial health effects, like protective role in cardiovascular diseases and cancer, also exhibit antimicrobial (including antiviral, antibacterial, antifungal), and antiallergenic activity (Hokkanen et al., 2009; Trumbeckaite et al., 2013; Yamaura et al., 2011). Less attention has been paid to the chemical composition of leaves and stems as they are not widely used. However, according to our HPLC analysis (Table 1), it seems that $V$. myrtillus leaves contain as high amounts of phenolic compounds as berries. Most of the detected phenols were hydroxycinnamic acids as was calculated based on the chlorogenic acid content. VLE also contained quite a high amount of hydroxybenzoic acids and flavanols expressed as gallic acid equivalents (Table 1). Frangula alnus (Rhamnus frangula), called Alder Buckthorn is a shrub commonly present across Poland. It occurs in a variety of forest communities - from dry coniferous forests, through the deciduous and mixed forests to swampy places. F. alnus bark (Cortex frangulae) is regarded as herbal material, serving as an ingredient in many herbal mixtures for the preparation of decoction. It stimulates laxative action and bowel peristalsis. Therefore, it is used in chronic constipation. F. alnus bark contains various biologically active substances, like anthraquinones (e.g. frangulin, also known as rhamnoxantin), flavonoids, tannins and saponins (Kharlamova et al., 2009; Manojlovic et al., 2005). As shown in Table 1, HPLC analysis of FBE indicated high total content of phenols with majority of hydroxybenzoic acids and flavanols, expressed as gallic acid equivalents. In contrast to $V$. myrtillus extract, extract from $F$. alnus contained both, condensed tannins (proanthocyanidins) and hydrolyzable tannins (ellagitannins).

Both plant-derived extracts tested have not yet found a practical and clinically approved application in the treatment of bacterial infections. Generally, a little research concerns the antimicrobial activity of Cortex frangulae. It was shown, that $F$. alnus extract possesses anti-fungal properties with the rate of growth inhibition between $25 \%$ and $68 \%$ for Penicillium verrucosum and Mucor mucedo, respectively (Manojlovic et al., 2005). Whereas anthraquinones and synthesized frangula-emodine derivatives used at micromolar concentrations are able to inhibit HIV-1 polymerase and $\mathrm{RNase} H$ functions, showing anti-viral properties (Kharlamova et al., 2009). However, the detected high content of hydroxybenzoic acids and flavanols as gallic acid equivalents 
Table 2. Minimum inhibitory concentration (MIC) and minimum bactericidal concentration (MBC) of the phytocompounds for S. aureus ATCC 29213 reference strain and S. aureus H9 clinical strain, determined by a microdilution broth assay accompanied by assessment of bacterial growth on solid media.

\begin{tabular}{l|llll}
\hline & \multicolumn{3}{l}{$\begin{array}{l}\text { S. aureus } \\
\text { ATCC } 29213\end{array}$} & \multicolumn{2}{l}{ S. aureus H9 } \\
\hline$[\mu \mathrm{g} / \mathrm{mL}]$ & MIC & MBC & MIC & MBC \\
\hline Plant extracts: & & & & \\
\hline VLE (V. myrtillus) & 1500 & 1500 & 750 & 750 \\
\hline FBE (F. alnus) & 750 & 1500 & 750 & 750 \\
\hline Commercial phytochemicals: & & & & \\
\hline Gallic acid & 125 & 125 & 62,5 & 62.5 \\
\hline Carvacrol & 250 & 500 & 250 & 500 \\
\hline Oleanolic acid & $>750$ & $>750$ & $>750$ & $>750$ \\
\hline
\end{tabular}

(mainly in FBE) may suggest a strong antibacterial activity. Gallic acid is a type of phenolic acid, known as 3,4,5-trihydroxybenzoic acid, found in sumac, witch hazel, tea leaves, oak bark, and many other plants. It possesses a relevant antioxidant activity used to protect human cells against oxidative damage, and shows cytotoxicity against cancer cells (Appeldoorn et al., 2005). Gallic acid and its dimeric derivative ellagic acid, are found in a free form or as part of gallo- and ellagitannins. Salts and esters of gallic acid called 'gallates' are best known in the context of antimicrobial activity. Examples of gallic acid derivatives are flavan-3-ols present in green tea: epicatechin gallate (ECG), epigallocatechin gallate (EGCG) or gallocatechin gallate (GCG) (Al-Zahrani, 2012). Our study confirmed the literature data on the antimicrobial activity of gallic acid, which proved to be the strongest compound acting against staphylococci among all tested commercial phytochemicals (Table 2). Oleanolic acid exhibited much lower activity against $S$. aureus. Because of poor solubility of oleanolic acid and the need

Table 3. Analysis of phytocompound cytotoxicity towards mouse fibroblasts line L929 - determination of the cytotoxicity index (IC50) using LDH Cytotoxicity Kit and calculation of the biocompatiblity index (BI).

\begin{tabular}{|c|c|c|c|c|}
\hline & $\begin{array}{l}\text { Time } \\
{[\mathrm{h}]}\end{array}$ & $\begin{array}{l}\mathrm{IC}_{50} \pm \mathrm{SD}^{*} \\
{[\mu \mathrm{g} / \mathrm{mL}]}\end{array}$ & $\mathrm{Bl}^{* *}(\mathrm{a})$ & $\mathrm{Bl}^{* *}(\mathrm{~b})$ \\
\hline \multicolumn{5}{|l|}{ Plant extracts: } \\
\hline \multirow{2}{*}{ VLE (V. myrtillus) } & 0.5 & $1144.5 \pm 18.0$ & 0.763 & 1.526 \\
\hline & 24 & $2041.1 \pm 587.1$ & 1.361 & 2.721 \\
\hline \multirow{2}{*}{ FBE (F. alnus) } & 0.5 & $1877.8 \pm 617.9$ & 1.252 & 2.504 \\
\hline & 24 & $1357.1 \pm 168.8$ & 0.905 & 1.809 \\
\hline \multicolumn{5}{|l|}{ Phytochemicals: } \\
\hline \multirow{2}{*}{ Gallic acid } & 0.5 & $135.3 \pm 32.6$ & 1.082 & 2.164 \\
\hline & 24 & $326.1 \pm 98.9$ & 2.608 & 5.217 \\
\hline \multirow{2}{*}{ Carvacrol } & 0.5 & $425.7 \pm 393.4$ & 0.851 & 0.851 \\
\hline & 24 & $115.1 \pm 72.5$ & 0.230 & 0.230 \\
\hline \multirow{2}{*}{ Oleanolic acid } & 0.5 & $1128.7 \pm 355.5$ & 1.505 & 1.505 \\
\hline & 24 & $201.5 \pm 9.3$ & 0.269 & 0.269 \\
\hline
\end{tabular}

* $\mathrm{IC}_{50}$ is mean value from two independent experiments each performed in duplicate \pm standard deviation (SD);** Bl was calculated as: $\mathrm{BI}$ $=I C_{50} / \mathrm{MBC}$, based on $\mathrm{MBC}$ of phytochemicals determined for $S$. aureus ATCC 29213 (a) or S. aureus H9 (b) strain and mean value of $I C_{50}$ for mouse fibroblasts. to prepare its primary solution in 100\% DMSO (biocidal for all microorganisms), there was no possibility to test oleanolic acid at a concentration higher than $750 \mu \mathrm{g} /$ $\mathrm{mL}$. Both tested plant extracts also showed strong antistaphylococcal activity with MIC range (depending on the strain) $750-1500 \mu \mathrm{g} / \mathrm{mL}$ (Table 2). It is worth noting that $S$. aureus $\mathrm{H} 9$ clinical isolate selected for this experiment is a member of an important group of "alert" human pathogens - MRSA (methicillin resistant $S$. aureus). Therefore, we have shown a significant direct biocidal activity of the extracts from $V$. myrtillus leaves and $F$. alnus bark against Gram-positive bacteria, including the multidrug-resistant $S$. aureus strain. Antimicrobial properties of plant products are determined on the basis of a susceptibility test by demonstrating MIC in the range of 100 to $1000 \mu \mathrm{g} / \mathrm{ml}$ (Tegos et al., 2002). However, plantderived extracts tested contained a mixture of various phenolic derivatives and other waste substances. Thus, the obtained values of MIC/MBC equal to $750 \mu \mathrm{g} / \mathrm{mL}$ should be considered very promising.

In the light of the knowledge of the ever-increasing resistance of pathogens towards classic antibiotics and the participation of their aggregates/biofilms in the development of many pathological changes, it seems necessary to design new approaches for the therapy efficient against the microorganisms and their communities. Such study may include a search for substances which have not only a direct biocidal effect, but also exhibit synergistic activity with available pharmacological agents, restrict the expression of microbial virulence factors, prevent microbial adhesion and aggregation or activate host immune defense mechanisms designed to combat infections (Budzyńska et al., 2011; Cushnie and Lamb, 2011; Gauwerky et al., 2009; Kurlenda and Grinholc, 2012; Kuźma et al., 2012). Several studies have suggested that phytocompounds, besides their direct biostatic/biocidal activity, can also enhance effects of other biocides (antibiotics) by increasing permeability of microbial cell walls for antibiotic penetration or blocking specific mechanisms of drug resistance. They can deactivate enzymes that degrade antibiotics, impair MDR efflux pumps, or inhibit synthesis of selected envelope proteins of resistant bacteria (Aqil et al., 2005; Cushnie \& Lamb, 2011; Gibbons, 2008; Nguyen \& Graber, 2010; Palombo, 2011; Rafii \& Shahverdi, 2007). Some phytocompounds exhibit direct microbicidal effects comparable to those of antibiotics. For example, it has been found that an extract from Myrtus communis leaves inhibits, similarly to the widely used pharmacological complex trimethoprim-sulfamethoxazole, growth of over $99 \%$ of the studied clinical isolates of S. aureus (Gholamhoseinian et al., 2009). Essential oils of Salvia officinalis (sage), Salvia triloba (sage shrub), Origanum minutiflorum (wild oregano), Origanum onites (oregano), Thymbra spicata (black thyme), Satureja cuneifolia (wild savory) and their components such as carvacrol efficiently inhibited growth of $S$. aureus (Alviano and Alviano, 2009). Moreover, it was demonstrated that some of these compounds are also active against the biofilm form of microorganisms, often interfering at the stage of their initial adhesion and aggregation (Chaieb et al., 2011). In our previous study we showed that plant-derived products, such as diterpenoids salvipisone and aethiopinone from Salvia sclarea hairy roots, taxodione-derivative isolated from Salvia austriaca roots, essential oils of Lavendula angustifolia, Melaleuca alternifolia, Melissa officinalis and their major constituents: linalool, linalyl acetate, $\alpha$-terpineol, terpinen-4-ol, preparations obtained from Humulus lupulus L. display promissing activity against Staphylococcus biofilm. These products influenced 

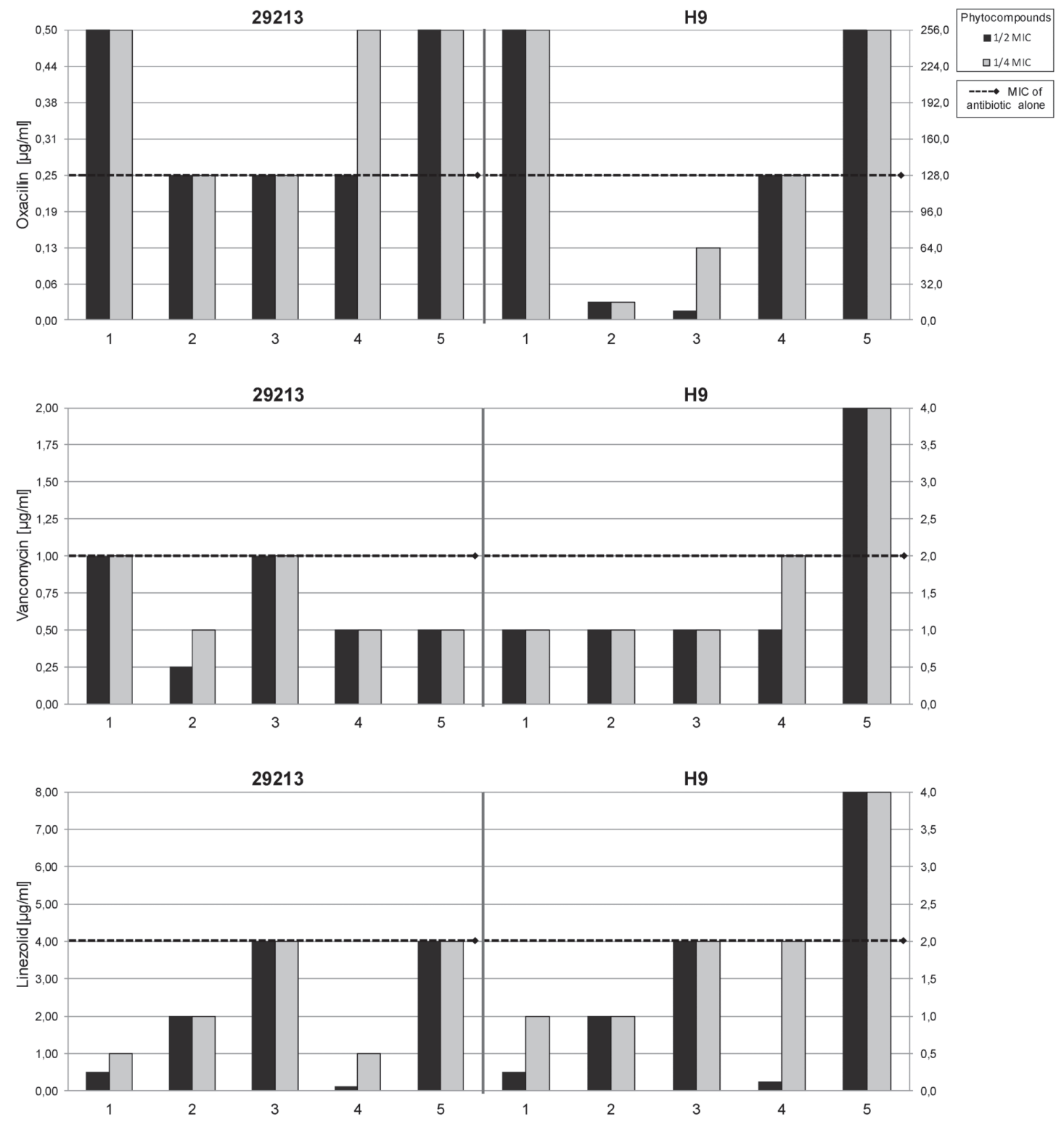

Figure 1. Synergistic effect of phytocompounds $(1-$ gallic acid; 2 - carvacrol; 3 - oleanolic acid; 4 - VLE; 5 - FBE) used at $1 / 2$ and $1 / 4$ MIC with oxacillin (A), vancomycin (B) or linezolid (C) against S. aureus ATCC 29213 and S. aureus H9 evaluated by microdilution method.

both, staphylococcal adhesion and biofilm development, as well as were capable of partial destruction and eradication of mature 24-h-old biofilms (Budzyńska et al., 2011; Kuźma et al., 2012; Różalski et al., 2013; Walencka et al., 2007).

The current paradigm in the discovery of novel promising antimicrobial therapeutics postulates their targeting of pathogen virulence factors/abilities rather than direct biocidal activity, and their synergistic effect with classic drugs (Budzyńska et al., 2011; Cushnie \& Lamb, 2001; Fankam et al., 2011; Gauwerky et al., 2009; Kurlenda \& Grinholc, 2012; Nguyen \& Graber, 2010; Rafii \& Shahverdi, 2007). In our research we used vancomycin and linezolid (antibiotics recommended for treatment of staphylococcal infections) to study possible synergy of the tested phytocompounds with these drugs. We also included oxacillin to examine the influence of plant-derived preparations on the status of $S$. aureus drug resistance one of important staphylococcal virulence factors. Here, we report on the possibility of enhancing antimicrobial activities of classic antibiotics in the presence of commercial pytocompounds or plant-derived extracts used at $1 / 2$ and $1 / 4$ MIC. When VLE and FBE were added into the medium together with the antibiotics, the MICs of vancomycin (glycopeptide) and linezolid (oxazolidinone) but not oxacillin (beta-lactam) were decreased (Fig. 1). The obtained results seem to be very important especially since the use of vancomycin and linezolid has recently increased. Both antibiotics are mainly administered to patients during hospitalization that often develop $S$. aureus (including MRSA) infections. The best example is life-threatening hospital-aquired pneumonia - a type of infection frequently aquired in intensive care units and mostly caused by these pathogens (Kalil et al., 2013). V. myrtillus leaves extract demonstrated the best synergistic activity together with linezolid, whose MIC was reduced 16-32x depending on the tested strain. It partially corresponded with the result obtained for gallic acid - the phytocompound being the representative of the polyphenols group, which was described as the most prominent 
component of the plant-derived extracts tested. MIC of linezolid against both $S$. aureus strains was reduced $8 \mathrm{x}$ in the presence of gallic acid at $1 / 2$ MIC (Fig. 1). Linezolid acts as an inhibitor of protein synthesis by blocking the 23S ribosomal subunit (Kalil et al., 2013). Since many plant products have been demonstrated to affect microbial cell wall and membrane integrity, it can be suggested that the synergy observed in this study is due to the facilitation of antibiotic penetration by phytocompounds. The results obtained for carvacrol seem to confirm this hypothesis. Based on $\mathrm{IC}_{50}$ (Table 3), carvacrol expressed a higher cytotoxic effect on eukaryotic cells, and probably also on bacterial cells. At the same time, it was the best enhancer of antimicrobial activity of all antibiotics tested. MIC values of oxacillin, vancomycin and linezolid were decreeased $8 \times, 2-4 \times$ and $2 \times$, respectively, by adding carvacrol at sub-MIC (Fig. 1). Similar enhancement of antibiotic activity was observed by Rafii and Shahverdi (2007) using nitrofurantoin combined with essential oils against enterobacteria. On the other hand, the opposite effect of sub-MIC concentration of Tea Tree oil (Melaleuca alternifolia) reducing bacterial susceptibility to antibiotics was also demonstrated. The authors explained this phenomenon as microbial adaptation due to membrane changes inhibiting antibiotic penetration (Bakkali et al., 2008; McMahon et al., 2007). In our study such a mode of action was showed by gallic acid or FBE used together with oxacillin against both $S$. aureus strains (Fig. 1). Thus, the final effect of the phytocompound action on cell membranes can lead to enhanced bacterial susceptibility or resistance. It depends on many factors, including phytocompound concentration, dissolving, rate of diffusion, salt forming, even microbial inoculum and a chosen technique. Therefore, a detailed study of a specific phytocompound, antibiotic and group of microorganisms should be performed every time.

A great number of plant extract constituents are typical lypophiles. They are able to cross the cell wall and cytoplasmic membrane, often disrupting their structure. Biological activity of many pytocompounds is based on cell membrane permeabilization. Such a process occuring in microorganisms leads to a loss of ions, leakage of macromolecules, reduction of membrane potential and fluidity, decrease in the ATP pool, and finally to osmotic lysis and microbial death (Alviano \& Alviano, 2009; Bakkali et al., 2008; Cushnie \& Lamb, 2005; 2011; Martos et al., 2013; McMahon et al., 2007). Antimicrobial activity of phytocompounds may also derive from their pro-oxidative properties. Accumulation of reactive oxygen substances (ROS) inside cells causes oxigenation of macromolecules followed by metabolic disturbance and cell death (Alviano \& Alviano, 2009; Gholamhoseinian et al., 2009). Some studies pointed to flavonoids as compounds which are able to inhibit DNA synthesis (e.g. epigallocatechin, quercetin, rutin) or energy metabolism (e.g. retrochalacones, lonchocarpol A), causing a reduction in macromolecule synthesis (RNA, DNA, cell wall and proteins). It must, therefore, be assumed that phytochemicals may target different structures and physiological processes in bacterial cells (Cushnie \& Lamb, 2005; 2011; Gibbons, 2008). Similar cytotoxic effect leading to induction of apoptosis and necrosis can be also observed in eukaryotic cells. Cytotoxicity of many plant-derived compounds used at microbicidal concentrations is a major limitation in their application as antimicrobials in humans (Alviano \& Alviano, 2009; Bakkali et al., 2008). Therefore, it is necessary to test cytotoxicity of the preparations destined for human usage (Müller \& Kramer, 2008). In this study we used an in vitro method with mouse fibroblasts line L929 to estimate the concentration of phytocompounds causing cytotoxic effect in half a population of the cells tested $\left(\mathrm{IC}_{50}\right)$ during 0.5 and 24 hours of co-incubation. As we expected, plant-derived extracts exhibited much lower cytotoxicity than comercial phytochemicals (Table 3). Based on $\mathrm{IC}_{50}$ and $\mathrm{MBC}$ against $S$. aureus strains, the biocompatibility index (BI) was calculated. As it has been shown in Table 3, the BIs of plant extracts were $>1$ for almost all conditions, which indicated these phytocompounds as possessing relevant antimicrobial activity accompanied by a relatively low cytotoxic effect against eukaryotic cells. A similar result was obtained for gallic acid (regardless of the exposure time of L929 cells) and oleanolic acid affecting cells during $0.5 \mathrm{~h}$.

Recently, a growing concern is focused on the impasse of antibiotic therapy, resulting from increasing resistance of microorganisms to the available chemotherapeutic agents, as well as from participation of their biofilms in the development of pathological changes. Thus, there is an ongoing need to investigate new therapeutic strategies and innovative approaches for eradicating multidrug-resistant microorganisms and their biofilms. The use of plant extracts (alone or synergistically with conventional antibiotics) for this purpose is possible, but requires detailed research. The proposed study on an assessment of chemical composition of the newly-prepared plant extracts (from $V$. myrtillus leaves and F. alnus bark) and their biological activity, including antimicrobial, synergistic with other biocides and cytotoxic effect on mammalian cells gives a theoretical basis for future applications of these phytocompounds. We believe that the described results provide a reliable scientific background in this area and may serve as an explanation for the proposed alternative therapy of skin and soft tissue infections caused by a very dangerous human pathogen - S. aureus.

\section{Acknowledgements}

This study was supported by grant of the National Science Centre No. 2012/05/N/NZ7/01216 entitled "Biomedical analysis of alternative strategy to treat chronic wound infections. In vitro research using plant polyphenols".

\section{REFERENCES}

Alviano DS, Alviano CS (2009) Plant extracts: search for new alternatives to treat microbial diseases. Curr Pharmac Biotechnol 10: 106-21.

Al-Zahrani SHM (2012) Antibacterial activities of gallic acid and gallic acid methyl ester on methicillin-resistant Staphylococcus aureus. $J \mathrm{Am}$ Sci 8: 7-12.

Appeldoorn CCM, Bonnefoy A, Lutters BCH, Daenens K, van Berkel TJC, Hoylaerts MF, Biessen EAL (2005) Gallic acid antagonizes P-selectin-mediated platelet-leukocyte interactions. Implications for the French Paradox. Circulation 111: 106-112.

Aqil F, Khan MSA, Owais M, Ahmad I (2005) Effect of certain bioactive plant extracts on clinical isolates of B-lactamase producing methicillin resistant Staphylococcus aureus. J Basic Microbiol 45: 106-14.

Bakkali F, Averbeck S, Averbeck D, Idaomar M (2008) Biological effect of essential oils - A review. Food Chem Toxicol 46: 446-475.

Budzyńska A, Więckowska-Szakiel M, Sadowska B, Kalemba D, Różalska B (2011) Antibiofilm activity of selected plant essential oils and their major components. Polish I Microbiol 60: 35-41.

Chaieb K, Kouidhi B, Jrah H, Mahdouani K, Bakhrouf A. Antibacterial activity of thymoquinone, an active principle of Nigella sativa and its potency to prevent bacterial biofilm formation. BMC Complem Altern Med 11: 1-6. Available from: http://www.biomedcentral. com/1472-6882/11/29

Clinical and Laboratory Standards Institute (2009) Methods for dilution antimicrobial susceptibility tests for bacteria that grow aerobically. Approved standard M07-A8 8th edn, Vol 29, No 2, pp 5-30. Wayne, USA. 
Cushnie TP, Lamb AJ (2005) Antimicrobial activity of flavonoids. Int J Antimicr Agents 26: 343-356.

Cushnie TP, Lamb AJ (2011) Recent advances in understanding the antibacterial properties of flavonoids. Int I Antimicr Agents 39: 99-107.

Dyrby M, Westergaard N, Stapelfeldt H (2001) Light and heat sensitivity of red cabbage extract in soft drink model system. Food Chem 72: $431-437$.

Fankam AG, Kuete V, Voukeng IK, Kuiate JR, Pages J-M (2011) Antibacterial activities of selected Cameroonian spices and their synergistic effects with antibiotics against multidrug-resistant phenotypes. BMC Compl Altern Med 11: 104-114.

Fraga CG, Galleano M, Verstraeten SV, Oteiza PI (2010) Basic biochemical mechanisms behind the health benefits of polyphenols. Mol Asp Med 31: 435-45.

Gauwerky K, Borelli C, Korting HC (2009) Targeting virulence: A new paradigm for antifungals. Drug Disc 14: 214-222.

Gholamhoseinian N, Mansouri S, Rahighi S (2009) Effects of sub-inhibitory concentration of Myrtus communis leave extracts on the induction of free radicals in Staphylococcus aureus: a possible mechanism for the antibacterial action. Asian J Plant Sci 8: 551-556.

Gibbons S (2008) Phytochemicals for bacterial resistance-strengths, weaknesses and opportunities. Planta Medica 74: 594-602.

Hartzfeld PW, Forkner R, Hunter MD, Hagerman AE (2002) Determination of hydrolyzable tannins (gallotannins and ellagitannins) after reaction with potassium iodate. I Agric Food Chem 50: 1785-1790.

Hokkanen J, Mattila S, Jaakola L, Pirttila AM, Tolonen A (2009) Identification of phenolic compounds from lingonberry (Vaccinium vitis-idaea L.), bilberry (Vaccinium myrtillus L.) and hybrid bilberry (Vaccinium intermedium Ruthe L.) leaves. I Agric Food Chem 57: 9437-9447.

Kalil AC, Klompas M, Haynatzki G, Rupp ME (2013) Treatment of hospital-acquired pneumonia with linezolid or vancomycin: a systematic review and meta-analysis. BMJ Open 3: doi: 10.1136/bmjopen-2013-003912

Kharlamova T, Esposito F, Zinzula L, Floris G, Cheng Y-Ch, Dutschman G, Tramontano E (2009) Inhibition of HIV-1 ribonuclease $\mathrm{H}$ activity by novel frangula-emodine derivatives. Med Chem 5: 398-410.

Kurlenda J, Grinholc M (2012) Alternative therapies in Staphylococcus aureus diseases. Acta Biochim Polon 59: 171-184.

Kuźma L, Wysokińska H, Różalski M et al. (2012) Antimicrobial and anti-biofilm properties of new taxidione derivative from hairy roots of Salvia austriaca. Phytomed 19: 1285-1287.

Manojlovic NT, Solujic S, Sukdolak S, Milosev M (2005) Antifungal activity of Rubia tinctorum, Rhamnus frangula and Caloplaca cerina. Fitoter 76: $244-246$

Martos J, Luque CMF, González-Rodriguez MP, Arias-Moliz MT, Baca P (2013) Antimicrobial activity of essential oils and chloroform alone and combinated with cetrimide against Enterococcus faecalis biofilm. Europ J Microbiol Immunol 3: 44-48.

McMahon MA, Blair IS, Moore JE, McDowell DA (2007) Habituation to sub-lethal concentrations of tee tree oil (Melalenca alternifolia) is associated with reduced susceptibility to antibiotics in human pathogens. I Antimicrob Chemother 59: 125-127.

Müller G, Kramer A (2008) Biocompatibility index of antiseptic agents by parallel assessment of antimicrobial activity and cellular cytotoxicity. I Antimirob Chemother 61: 1281-1287.

Nguyen HM, Graber CJ (2010) Limitations of antibiotic options for invasive infections caused by methicillin-resistant Staphylococcus aureus is combination therapy the answer? I Antimicrob Chemother 65: 24-36.

Palombo EA (2011) Traditional medicinal plant extracts and natural products with activity against oral bacteria: Potential application in the prevention and treatment of oral diseases. Evid-Based Complem Altern Med 20: article ID 680354, 15 pages.

Rafii F, Shahverdi AR (2007) Comparison of essential oils from three plants for enhancement of antimicrobial activity of nitrofurantoin against enterobacteria. Chemother 53: 21-25.

Rösch D, Bergmann M, Knorr D, Kroh LW (2003) Structure-antioxidant efficiency relationships of phenolic compounds and their contribution to the antioxidant activity of sea buckthorn juice. I Agric Food Chem 51: 4233-4239.

Różalski M, Micota B, Sadowska B, Stochmal A, Jędrejek D, Więckowska-Szakiel M, Różalska B (2013) Antiadherent and antibiofilm activity of Humulus lupulus L. derived products: new pharmacological properties. BioMed Res Intern 7 pages [DOI: 10.1155/2013/101089].

Swain T, Hillis WE (1959) The phenolics constituents of Prunus domestica II. I Sci Food Agric 10: 135-138.

Tegos G, Stermitz FR, Lomovskaya O, Lewis K (2002) Multidrug pump inhibitors uncover remarkable activity of plant antimicrobials. Antimicrob Agents Chemother 46: 3133-3141.

Trumbeckaite S, Burdulis D, Raudone L, Liobikas J, Toleikis A, Janulis V (2013) Direct effect of Vaccinium myrtillus $L$. fruit extracts on rat heart mitochondrial functions. Phytother Res 27: 499-506.

Walencka E, Różalska S, Wysokińska H, Różalski M, Kuźma Ł, Różalska B (2007) Salvipisone and aethiopinone from Salvia sclarea hairy roots modulate staphylococcal antibiotic resistance and express anti-biofilm activity. Planta Med 73: 545-551.

Yamaura K, Shimada M, Ueno K (2011) Anthocyanins from bilberry (Vacinium myrtillus L.) alleviate pruritus in a mouse model of chronic allergic contact dermatitis. Pharmacognosy Res 3: 173-177. 